\title{
Therapeutic Effects of Essential Oil from Waste Leaves of Psidium guajava L. against Cosmetic Embarrassment Using Phylogenetic Approach
}

\author{
Ahsan Kamran ${ }^{1}$, Rohit Kumar Mishra ${ }^{1}$, Rita Gupta ${ }^{2}$, Awadhesh Kumar ${ }^{1}$, Ashok Kumar Bajaj ${ }^{3}$, \\ Anupam Dikshit ${ }^{1}$
}

${ }^{1}$ Biological Product Laboratory, Department of Botany, University of Allahabad, Allahabad, India; ${ }^{2}$ Department of Horticulture, Aromatic \& Medicinal Plants, Mizoram University, Aizawl, India; ${ }^{3}$ Department of Dermatology and Veneral Diseases, M.L.N. Medical College, Allahabad, India.

Email: anupambplau@rediffmail.com

Received February $18^{\text {th }}, 2012$; revised March $2^{\text {nd }}, 2012$; accepted March $20^{\text {th }}, 2012$

\begin{abstract}
Medicinal plants are facing threats due to loss of habitat and overexploitation of knows species. Therefore the present work shows utilization of essential oil from discarded leaves of Psidium guajava Linn. against human dermatophytic fungi Trichophyton rubrum, T. mentagrophytes, Trichophyton violaceum, Trichophyton tonsurans, Epidermophyton floccosum, Microsporum gypseum and Microsporum canis. The oil was found to be fungicidal at $3.0 \mu 1 / \mathrm{ml}$ and it tolerated heavy inoculum of pathogens at fungicidal concentrations. The fungicidal activity of the oil was thermostable, up to $70^{\circ} \mathrm{C}$ and shelf life was found to be six months, which was maximum the time taken into consideration. The oil having cineole, caryophyllane, copaene, azulene and eucalyptol as main constituents, exhibited broad fungicidal activity. The oil did not show any adverse effect on mammalian skin upto 5\% concentration. Phylogeny of the dermatophytes with respect to toxicity of the oil has also been discussed using molecular data. The cost effective formulation from waste leaves can be exploited after undergoing double blind successful multicentral topical testing.
\end{abstract}

Keywords: Essential Oil; Dermatophytes; Phylogeny; Discarded Leaves; Psidium guajava L.; Trichophyton rubrum; T. mentagrophyte

\section{Introduction}

Humid and unhygienic environment in tropical and subtropical countries are the main reason of a common cosmetic problem - tinea pedis (ring worm of feet), caused dominantly by Trichophyton rubrum followed by $T$. mentagrophytes and Epidermophyton floccosum [1-3]. Among these, ringworm infections are most prevalent and are named after the body parts affected. It is caused by a closely related group of fungi known as dermatophytes which have the ability to utilize keratin as a nutrient source by an enzyme keratinase. Tinea pedis caused by anthropophilic dermatophytes by shedding of skin scales which are containing viable infectious hyphal element of the fungus. The increased use of synthetic antifungal agents in recent years has resulted in the development of resistance against these drugs [4]. Moreover these antifungal drugs are largely non renewable petro products that are non biodegradable and have adverse effect and residual toxicity [5], apart from being fungistatic in nature. In recent years, plant secondary metabolites rapidly became alternate source of antifungal drugs [6], as they are mostly biodegradable and are devoid of side effects [7]. Work on volatile plant products is gaining momentum $[8,9]$ and worldwide spending on finding new anti-infective agents is expected to increase [10], as a result sales of botanical medicines has been increased in recent years [6].

Although too much emphasis has been given on the medicinal and aromatic plant species for discovering in them some new drugs and other compound of commercial interest, yet little or no concerted effort has been made for their conservation. Unfortunately medicinal plants are facing threats as well, due to loss of habitat and overexploitation of known species and efforts have been started to conserve them [11]. Keeping these views in mind, the present work was undertaken to explore the antifungal potentiality of essential oil of discarded plant leaves.

Psidium guajava Linn belonging to the family Myrtaceae is a native plant of tropical America. A survey of the literature shows $P$. guajava $\mathrm{L}$. is mainly known for its antispasmodic and antimicrobial properties in the treatment of diarrhea [12] and dysentery [13], apart from being used an anti-inflammatory, for diabetes, hypertension, carries, wounds, pain relief and reducing fever [14]. Leaves 
of this plant have been reported to contain several compounds such as various flavonoids [15], tannins [16] and terpenoids [17]. Quercetin is the best known flavonoid from guava leaves [15]. GC/MS analysis shows presence of cineole, caryophyllene, copaene, azulene and eucalyptol as the major constituents besides sixty others $[18,19]$.

Allahabad city $\left(25^{\circ} 28^{\prime} \mathrm{N}\right.$ and $\left.81^{\circ} 54^{\prime} \mathrm{E}\right)$ is famous for its so many verities of delicious guavas [20]. During November to February, huge amount of guava are sold in the local market and also exported to neighboring cities and states. During the process leaves are also plucked to put as a cushion and packing of the fruits to avoid injury. After the guava fruits are sold, the sellers discard the leaves. In the present investigation, these discarded leaves were collected from the local market and the extracted essential oil was tested against the dominant dermatophytesTrichophyton rubrum (Castellani) Sabouraud, Trichophyton mentagrophytes (Robin) Blanchard, Trichophyton violaceum Sabouraud, Trichophyton, tonsurans Malmsten, Microsporum canis Bodin, Microsporum gypseum (Bodin) Guiart et Grigorakis and Epidermophyton floccosum (Harz) Langeron \& Miloch.

\section{Materials and Methods}

\subsection{Extraction of Essential Oil}

The essential oil was extracted from the leaves of Psidium guajava L. by hydrodistillation using a Clevenger's apparatus [21]. Clear greenish yellow oil was obtained on the top of the aqueous distillate, which was separated from the latter and dried over anhydrous sodium sulphate. The physiochemical properties of the oil were determined by the technique described by Langenau [22].

\subsection{GC-MS Analysis}

Gas Chromatography analysis of the oil was performed on a Perkin-Elmer GC 8500, using a fused capillary column $(25 \mathrm{~m} \times 0.55 \mathrm{~mm}$ i.d., film thickness $0.25 \mathrm{um})$, coated with dimethtyl siloxane (BP-1). The oven temperature was programmed at $60^{\circ} \mathrm{C}$ to $220^{\circ} \mathrm{C}$ at $5^{\circ} \mathrm{C} / \mathrm{min}$. then held isothermal at $220^{\circ} \mathrm{C}$ for $15 \mathrm{~min}$. injector temperature, $250^{\circ} \mathrm{C}$, detector temperature, $300^{\circ} \mathrm{C}$, carrier gas, nitrogen at a linear velocity of 10 psi:split, 1:80.

GC-MS data were obtained on a Shimazdu QP-2000 mass spectrometer at $70 \mathrm{ev}$ and $250^{\circ} \mathrm{C}$. GC column: Ulbon HR-1 equivalent to OV-1, fused silica capillary column $0.25 \mathrm{~mm} \times 50 \mathrm{~m}$, film thickness $0.25 \mathrm{um}$. The initial temperature was $100^{\circ} \mathrm{C}$ for $7 \mathrm{~min}$. and heated at $5^{\circ} \mathrm{C} / \mathrm{min}$ to $250^{\circ} \mathrm{C}$. Carrier gas helium at a flow rate of $2 \mathrm{ml} / \mathrm{min}$.

\subsection{Procurement of Test Dermatophytes}

Seven selected dermatophytes viz. Trichophyton rubrum,
Trichophyton mentagrophytes, Trichophyton violaceum, Trichophyton, tonsurans, Microsporum canis, Microsporum gypseum and Epidermophyton floccosum were obtained from Microbial Type Culture Collection (MTCC), IMTECH Chandigarh, India. The cultures of were maintained on Sabouraud Dextrose Agar (SDA) medium (pH 5.6) throughout the study.

\subsection{Determination of Minimum Inhibitory Concentrations (MICs)}

The test pathogens were obtained from Microbial Type Culture Collection, Institute of Microbial Technology Chandigarh. The minimum inhibitory concentrations (MICs) of the oil against test pathogens were determined in-vitro using poisoned food technique [23] with slight modification [24]. The requisite quantity of the oil samples were mixed in acetone ( $2 \%$ of the required quantity of the medium) and then added in pre-sterilized Sabouraud Dextrose Agar (SDA) medium, pH 5.6. In control sets, sterilized water (in place of the oil) and acetone were used in the medium in appropriate amounts. Mycelial discs of 5 $\mathrm{mm}$ diameter, cut out from the periphery of 7 days old cultures, were aseptically inoculated upside-down on the agar surface of the medium. Inoculated petri plates were incubated at $27^{\circ} \mathrm{C} \pm 1{ }^{\circ} \mathrm{C}$ and the observations were recorded on the seventh day. Percentage of fungal growth inhibittion (FGI\%) was calculated according to the formula:

$$
\mathrm{FGI} \%=\frac{\mathrm{dc}-\mathrm{dt}}{\mathrm{dc}} \times 100
$$

where $\mathrm{dc}=$ fungal colony diameter in control sets, $\mathrm{dt}=$ fungal colony diameter in treatment sets.

\subsection{Determination of Minimum Fungistatic/Fungicidal Concntrations}

The minimum fungistatic/fungicidal concentrations of the oil at minimum inhibitory concentrations (MICs) were ascertained by the method of Garber and Houston, [25]. This was done by re-inoculating the inhibited fungal discs at MICs on SDA medium. Fungal growth on the seventh day indicated a fungistatic nature, while the absence of fungal growth denoted fungicidal action of the oil.

\subsection{Effect of Inoculum Density}

The effect of inoculum density (increased progressively up to 30 discs in multiples of five, each of $5 \mathrm{~mm}$ diameter) of the test pathogens on MICs of the oil was determined following the procedure of Dikshit and Dixit [26]. The effect of physical factors viz., temperature and expiry of toxicity during storage of the oil, was evaluated according to Shahi, et al. [24]. Five lots of $5 \mathrm{ml}$ oil were kept in small vials and exposed to $40^{\circ} \mathrm{C}, 60^{\circ} \mathrm{C}$ and $80^{\circ} \mathrm{C}$ 
temperatures in an incubator for $1 \mathrm{~h}$. Antidermatophytic activity was then tested at MICs by the poisoned food technique. Expiry of toxicity of the oil was determined by storing the oil at room temperature and testing antidermatophytic activity at MICs at regular intervals of 60 days up to 6 months.

\subsection{Determination of Minimum Killing Time}

The Minimum Killing Time (MKT) of the oil was determined by the mycelial disc killing technique (MDKT) [24]. Two treatment sets were maintained, one with pure oil and the other with the minimum fungicidal concentrations (MCCs) of the oil. The treatment set using MCCs of the oil was prepared by mixing the required quantity of the oil samples in acetone (5\% of the total quantity of the treatment solution) and then adding this to the appropriate quantity of distilled water. Simultaneously, controls were maintained using sterilized water (in place of the oil) and acetone, adding into the distilled water in appropriate quantities. Mycelial discs of $5 \mathrm{~mm}$ diameter, cut out from the periphery of 7 days old cultures of the test pathogens, were aseptically placed in the culture tubes of different treatment and control sets. These mycelial discs were taken out of the tubes at different time intervals and washed immediately in the washing solution (containing acetone: sterilized distilled water, 1:2) to remove the treatment solution. These washed mycelial discs were aseptically transferred upside-down to the Sabouraud Dextrose Agar (SDA) medium (pH 5.6) in the petri plates. The same procedure was followed with the control sets. The inoculated petri plates were incubated at $27^{\circ} \mathrm{C} \pm 1{ }^{\circ} \mathrm{C}$ and the observations recorded as an average value of five replicates on the seventh day. The percentage of fungal growth inhibition (FGI \%) was calculated according to the formula:

$$
\operatorname{FGI}(\%)=\frac{\mathrm{dc}-\mathrm{dt}}{\mathrm{dc}} \times 100
$$

The experiments were repeated twice, each containing five replicates, and the data presented here are based on their mean values.

\subsection{Patch Test Method for Irritatant Activity}

Patch test method of Roxburgh and Borrie, [5] was followed to find out the maximum tolerable concentrations (MTCs) for irritant activity of the oil by their topical application. People of both sexes aged 15 - 45 years were selected randomly and a group of 30 individuals of each sex was constituted. Circular areas of $5 \mathrm{~cm}^{2}$ on upper hairy and lower glabrous surface of the palms and $3 \mathrm{~cm}^{2}$ of neck region of each individual were first washed with distilled water followed by $70 \%$ ethyl alcohol and then allowed to dry for $5 \mathrm{~min}$. Five drops of the graded con- centrations of testing solution were applied to each individual separately for 3 weeks. The volunteers were not allowed to wash the applied area. Qualitative observations were recorded at intervals of $24 \mathrm{~h}$ for 3 weeks.

\subsection{Phylogenetic Study of Dermatophytes}

To find out why the oil is more effective against certain dermatophytic fungi, phylogenetic relationship of these dermatophytes have been studied including the genera Trichophyton, Microsporum and Epidermophyton, and identified the species using the base pair sequences of ITS1 $[27,28]$ Figure 1. The ITS1 sequences of the standard strains used in this study-Trichophyton mentagrophytes, accession no. $\mathrm{AB} 011463 ;$ T. rubrum, $\mathrm{AB} 011453 ;$ T. violaceum, AB017174; T. tonsurans; AB017172; Microsporum gypsem, AB017177; M. canis, AB017179 and Epidermatophyton floccosum, AB017181, as reported by the authors $[28,29]$ were aligned by using the Clustal W computer program [30] and GENETYX-MAC 10.1 software (Software Development Co., Ltd., Tokyo, Japan).

Phylogenetic trees were then constructed by the DNA maximum-likelihood (ML) method in the PHYLIP program (Phylogeny Inference Package), version 3.5c [31] and the neighbor-joining (NJ) [32] method in the NJPLOT program [33]. Bootstrap [34] analysis with the Clustal W program was performed by taking 1000 random samples from the multiple alignments.

\section{Results and Discussion}

Dermatophytes causes cosmetic problem and treating them has always been a difficult job as most antifungal synthetic agents are static in nature. Moreover there is increasing development of resistance against them. Workers like Stock [35] emphasized the need to discover powerful and specific antifungal agents on an increasing scale to combat fungal infections. Essential oils exhibiting wide range of antifungal activity, as suggested in the present investigation, may prove useful in the development of cheaper and potent antifungal substances against dermatophytes.

The waste leaves of Psidium guajava L. upon hydrodistillation yielded $0.4 \%$ essential oil. The constituents of essential oils from the leaves of Psidium guajava Linn on GC/MS analysis showed the presence of sixty compounds. The major components were Caryophyllene- $18.81 \%$, Copaene- $11.80 \%$, [1aR-(1a $\alpha-, 4 \mathrm{a} \alpha-, 7 \alpha-, 7 a \beta-, 7 \mathrm{~b} \alpha-)]$-decahydro-1,1,7-trimethyl-4-methylene-1H-cyclo-prop[e]azulene $-10.27 \%$ and Eucalyptol- $7.36 \%$ [18].

Further studies showed the presence of Guajavolide $(2 \alpha-, 3 \beta-, 6 \beta, 23$-tetrahydroxyurs-12-en-28,20 $\beta$-olide $)$ and Guavenoic acid (2 $\alpha-, 3 \beta-, 6 \beta-, 23$-tetrahydroxyurs-12,20(30)dien-28-oic acid) along with one known triterpene oleanolic acid as well [36]. The oil was characterized by various physicochemical properties (Table 1). 
Antidermatophytic spectrum of essential oil from the leaves of Psidium guajava

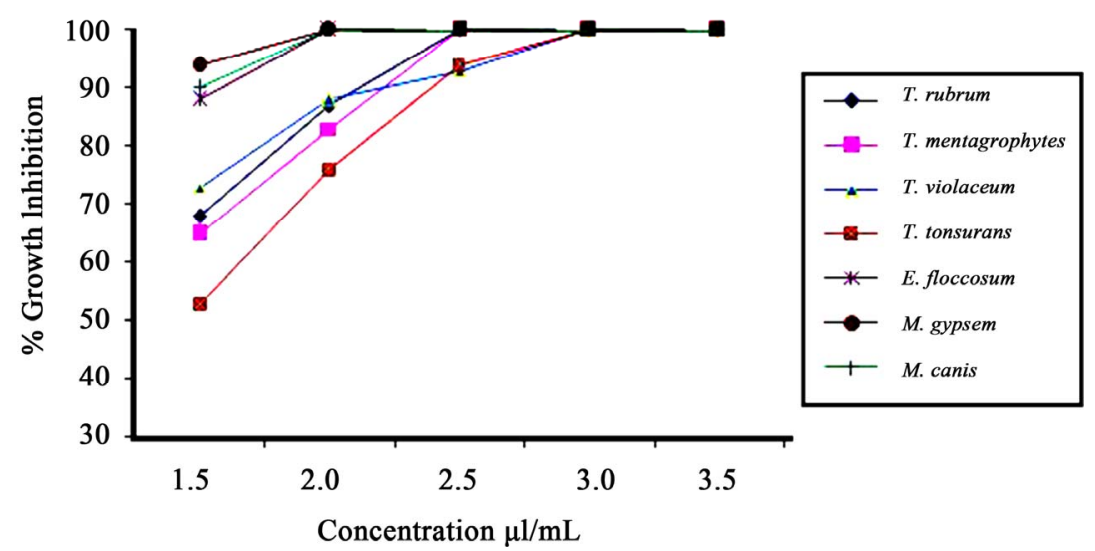

Figure 1. Graphical representation of antidermatophytic spectrum of Psidium guajava L. leaf essential oil.

\subsection{In-Vitro Studies of Selected Dermatophytes against Waste Leaves' Essential Oil from Psidium guajava $\mathbf{L}$.}

Many workers in India have studied the antifungal activeity of candidate substances employing qualitative assay techniques $[37,38]$ but have not described the nature of the toxic action (fungistatic/fungicidal). In the present work the minimum static and minimum inhibitory concentration was $2.5 \mu \mathrm{l} / \mathrm{ml}$ and $3.0 \mu \mathrm{l} / \mathrm{ml}$ against Trichophyton rubrum and Trichophyton mentagrophytes respectively.

The oil could withstand heavy doses of inocula up to 30 discs at their respective minimum inhibitory concentration (Table 2). The activity of the oil persisted even up to 6 months of storage and the oil was thermostable up to $80^{\circ} \mathrm{C}$. The pure oil killed the test pathogens Trichophyton rubrum and Trichophyton mentagrophytes in just $30 \mathrm{sec}$. while at its minimum inhibitory concentration it required 200 min (Table 2).

Work on controlling dermatophytosis using essential oils from various medicinal plants is going on worldwide. Recent works on essential oils e.g. Ligusticum chuanxiong essential oil exhibited strong antidermatophytic action against Trichophyton species such as, T. erinacei, T. mentagrophytes, T. rubrum, T. schoenleinii, T. tonsurans and T. soudanense [39]. Inouye, et al., [40] also using a wide variety of plant (Cinnamomum zeylanicum, Eugenia aromatica, Geranium maculatum, Lavandula angustifolia, Cymbopogon citratus, Origanum vulgare, Cymbopogon martinii, Mentha piperita, Melaleuca alternifolia and Thymus vulgaris) essential oils against $T$. mentagrophytes and T. rubrum. Allium sativum, A. cepa and $A$. fistulosum demonstrated strong antidermatophytic activity against three species of Trichophyton. This was confirmed by Pyun and Shin, [41]. At the same time, a
Table 1. Physicochemical properties of essential oil from the leaves of Psidium guajava $\mathrm{L}$.

\begin{tabular}{ccc}
\hline S. No. & Properties studied & Observations \\
\hline 1 & Plant height $(\mathrm{m})$ & $4-5$ (approx.) \\
2 & Oil yield (\%) & 0.4 \\
3 & Colour of the oil & Yellowish-green \\
4 & Specific gravity at $26^{\circ} \mathrm{C}$ & 0.9102 \\
5 & Refractive index at $23^{\circ} \mathrm{C}$ & 1.487 \\
6 & Specific rotation & $-13.1^{\circ}$ \\
7 & Ester value & 4.7 \\
8 & Solubility & Acetone \\
\hline
\end{tabular}

Table 2. In-vitro antidermatophytic properties of essential oil from waste leves of $P$. guajava $L$. against test pathogens Trichophyton rubrum and T. mentagrophytes.

\begin{tabular}{|c|c|c|c|c|}
\hline Properties & \multicolumn{4}{|c|}{ Mycelial growth inhibition (MGI-\%) } \\
\hline A. Conc. of oil $(\mu 1 / \mathrm{ml})$ & \multicolumn{2}{|c|}{ Trichophyton rubrum } & \multicolumn{2}{|c|}{ T. mentagrophytes } \\
\hline 3.5 & \multicolumn{2}{|c|}{$100^{\mathrm{c}}$} & \multicolumn{2}{|c|}{$100^{\mathrm{c}}$} \\
\hline 3.0 & \multicolumn{2}{|c|}{$100^{\mathrm{c}}$} & \multicolumn{2}{|c|}{$100^{\mathrm{c}}$} \\
\hline 2.5 & \multicolumn{2}{|c|}{$100^{\mathrm{s}}$} & \multicolumn{2}{|c|}{$100^{\mathrm{s}}$} \\
\hline 2.0 & \multicolumn{2}{|c|}{87} & \multicolumn{2}{|c|}{83} \\
\hline 1.5 & \multicolumn{2}{|c|}{68} & \multicolumn{2}{|c|}{65} \\
\hline $\begin{array}{l}\text { B. Effect of Inoculum } \\
\text { density (No. of } \\
\text { fungal discs) }\end{array}$ & \multicolumn{2}{|c|}{ Trichophyton rubrum } & \multicolumn{2}{|c|}{ T. mentagrophytes } \\
\hline 5 & \multicolumn{2}{|c|}{100} & \multicolumn{2}{|c|}{100} \\
\hline 10 & \multicolumn{2}{|c|}{100} & \multicolumn{2}{|c|}{100} \\
\hline 15 & \multicolumn{2}{|c|}{100} & \multicolumn{2}{|c|}{100} \\
\hline 20 & \multicolumn{2}{|c|}{100} & \multicolumn{2}{|c|}{100} \\
\hline 25 & \multicolumn{2}{|c|}{100} & \multicolumn{2}{|c|}{100} \\
\hline \multirow{2}{*}{$\begin{array}{l}\text { C. Minimum } \\
\text { killing time }\end{array}$} & Trichop & n rubrum & \multicolumn{2}{|c|}{ T. mentagrophytes } \\
\hline & PO & $\mathrm{MCC}$ & PO & $\mathrm{MCC}$ \\
\hline 200 Min. & 100 & 100 & 100 & 100 \\
\hline 100 Min. & 100 & 96 & 100 & 91 \\
\hline $50 \mathrm{Min}$. & 100 & 89 & 100 & 82 \\
\hline $30 \mathrm{Sec}$. & 100 & -- & 100 & -- \\
\hline
\end{tabular}


variety of medicinal and aromatic plants of commercial importance are currently facing extinction or severe genetic loss arising from increased demand of their products all over the world, and vastly increasing human population and extensive destruction of plant rich habitats. Therefore these findings are first, where the discarded guava leaves of no commercial value have been utilized to extract oil and their antidermatophytic use, thereby making it economical. The minimum static and minimum inhibitory concentration (MIC) of the oil was found to be $2.0 \mu \mathrm{l} / \mathrm{ml}$ and $2.5 \mu \mathrm{l} / \mathrm{ml}$ against test pathogens Microsporum gypseum and Trichophyton mentagrophytes respectively (Table 3 ).

Antimicrobial activity of Leptospermum petersonii, Syzygium aromaticum essential oils against a wide range of dermatophytes such as Trichophyton mentagrophytes, T. rubrum, Epidermophyton floccosum and Microsporum gypseum were also noted [42]. Likewise, different fractions, such as hexane, chloroform and essential oil of Ocimum gratissimum proved effective against Microsporum canis, M. gypseum, Trichophyton rubrum and $T$. mentagrophytes, Trichophyton rubrum [43]. Unlike the oil of Adenocalymma allicea where fungitoxicity expired after 21 days [44], fungitoxicity of Psidium guajava leaf essential oil persisted for 6 months, maximum time taken into consideration. In the present study, Psidium guajava L. leaf essential oil exhibited a broad spectrum antifungal activity against Trichophyton rubrum, T. mentagrophytes, Trichophyton violaceum, Trichophyton tonsurans, Epidermophyton floccosum, Microsporum gypseum and Microsporum canis at concentration in the range of $2.5-3.5$ $\mu \mathrm{l} / \mathrm{ml}$ (Figure 1).

The oil was compared with some prevalent synthetic antifungal drugs having Miconazole nitrate, Ketoconazole and Tonlaflat. The minimum static concentration of the oil was $2.5 \mu \mathrm{l} / \mathrm{ml}$ as compared to the MSC of these drugs, ranging from 5.0 to $6.0 \mu \mathrm{l} / \mathrm{ml}$ with exception of Tonlaflat $(0.4$ to $0.8 \mu \mathrm{l} / \mathrm{ml}$ ) (Table 4$)$.

Table 3. Antidermatophytic spectrum of essential oil from the leaves of Psidium guajava L.

\begin{tabular}{cccccc}
\hline \multirow{2}{*}{ Human pathogenic fungi } & \multicolumn{7}{c}{$\begin{array}{c}\text { Mycelial growth inhibition at various } \\
\text { concentrations }(\boldsymbol{\mu l} / \mathbf{m l})\end{array}$} \\
\cline { 2 - 6 } & $\mathbf{1 . 5}$ & $\mathbf{2 . 0}$ & $\mathbf{2 . 5}$ & $\mathbf{3 . 0}$ & $\mathbf{3 . 5}$ \\
\hline Trichophyton rubrum & 68 & 87 & $100^{\mathrm{s}}$ & $100^{\mathrm{c}}$ & $100^{\mathrm{c}}$ \\
T. mentagrophytes & 65 & 83 & $100^{\mathrm{s}}$ & $100^{\mathrm{c}}$ & $100^{\mathrm{c}}$ \\
Trichophyton violaceum & 73 & 88 & 93 & $100^{\mathrm{s}}$ & $100^{\mathrm{c}}$ \\
Trichophyton tonsurans & 53 & 76 & 94 & $100^{\mathrm{s}}$ & $100^{\mathrm{c}}$ \\
Epidermophyton floccosum & 88 & $100^{\mathrm{s}}$ & $100^{\mathrm{c}}$ & 100 & 100 \\
Microsporum gypseum & 94 & $100^{\mathrm{s}}$ & $100^{\mathrm{c}}$ & 100 & 100 \\
Microsporum canis & 90 & $100^{\mathrm{s}}$ & $100^{\mathrm{c}}$ & 100 & 100 \\
\hline
\end{tabular}

$\mathrm{s}=$ static, $\mathrm{c}=$ cidal
Table 4. Comparative efficacy of guava leaf essential oil with some synthetics.

\begin{tabular}{cccccc}
\hline \multirow{2}{*}{$\begin{array}{c}\text { Oil and trade } \\
\text { names of } \\
\text { antimycotic }\end{array}$} & Active & \multicolumn{4}{c}{ Concentrations $(\boldsymbol{\mu l} / \mathbf{m l})$} \\
\cline { 3 - 6 } drugs & principles & \multicolumn{2}{c}{ T. rubrum } & T. mentagrophytes \\
\cline { 3 - 6 } & & MSC & MCC & MSC & MCC \\
\hline Guava leaves & Essential oil & 2.5 & 3.0 & 2.5 & 3.0 \\
Dactarin & Miconazole nitrate & 5.0 & - & 6.0 & - \\
Nizral & Ketoconazole & 5.0 & - & 5.0 & - \\
Tenaderm & Tonlaflat & 0.4 & - & 0.8 & - \\
\hline
\end{tabular}

Synthetic drugs on one hand may give quick relief but on the other hand are only static in nature, having lots of side effects. Apart from being cidal in nature the essential oil is much cheaper and cost effective as compared to the synthetic formulation since it is obtained from waste leaves of Psidium guajava L. leaves. The oil did not show any irritation or adverse effect at $5 \%$ concentration up to three weeks.

\subsection{Phylogenetic Relationship of Dermatophytes}

The phylogenetic relationship of dermatophytic genera Trichophyton, Microsporum and Epidermophyton were demonstrated by using internal transcribed spacer 1 (ITS1) region ribosomal DNA sequences. The ITS1 sequences of the standard strains used in this study [28,29], were aligned by using the Clustal W computer program [30] and GENETYX-MAC 10.1 software (Software Development Co., Ltd., Tokyo, Japan). Phylogenetic trees were then constructed by the DNA maximum-likelihood (ML) method in the PHYLIP program (Phylogeny Inference Package), version 3.5c [31] and the neighbor-joining (NJ) [32], method in the NJPLOT program [33]. Bootstrap [34] analysis with the Clustal W program was performed by taking 1000 random samples from the multiple alignments. The result of phylogenetic relationship of dermatophytic genera was shown in unrooted Neigbour Joining Tree plot on the basis of their ITS1 sequences (Figure 2). The ITS1 sequences of 7 standard test strains were also determined to identify the species. All strains were successfully identified by comparison of their base sequences with those in the ITS1 DNA sequence database [30]. The Cladogram (Neigbour Joining Tree plot) of dermatophytes clearly indicate in Figure 3 that the Trichophyton mentagrophytes, T. rubrum, T. violaceum and $T$. tonsurans belonging to same genetical stock were having close inhibitory concentrations as compared to Microsporum gypsem, M. canis and Epidermatophyton floccosum. Mishra, et al., [45] has also discussed the phylogenetic relationships of the dental caries causing pathogens with respect to the toxicity of leaf essential oil of Micromeria biflora Benth. 


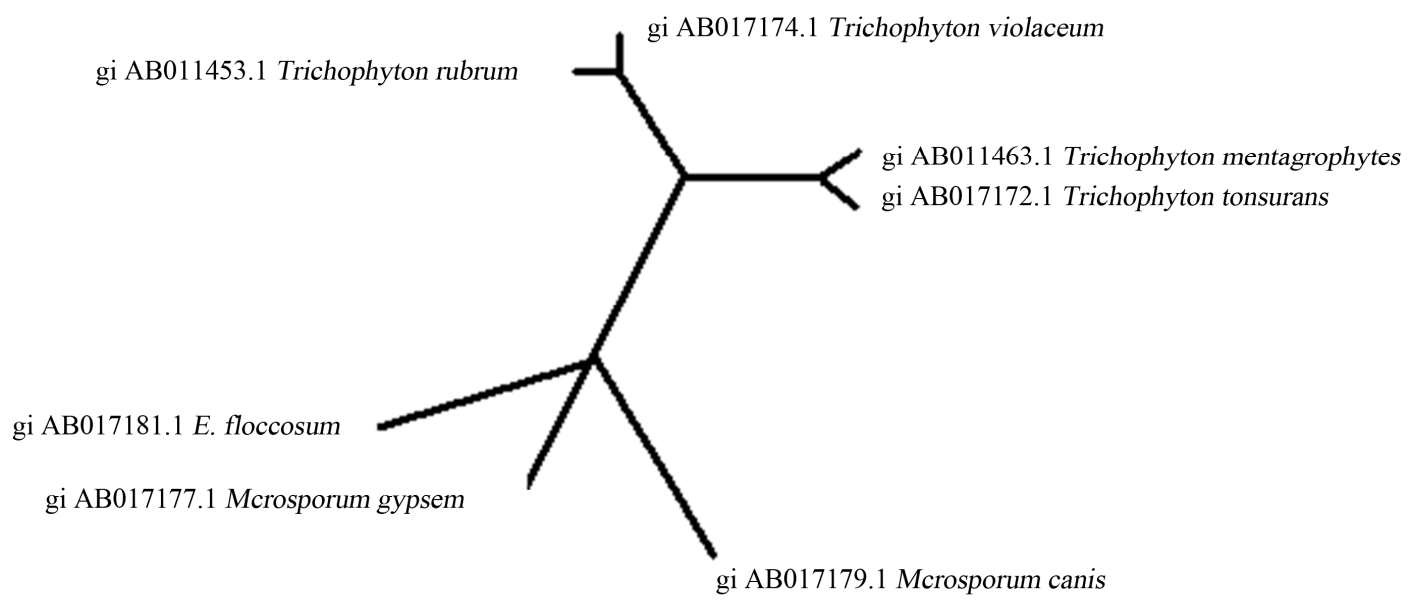

Figure 2. Unrooted Neigbour Joining Tree plot of dermatophytes on the basis of their ITS1 sequences.

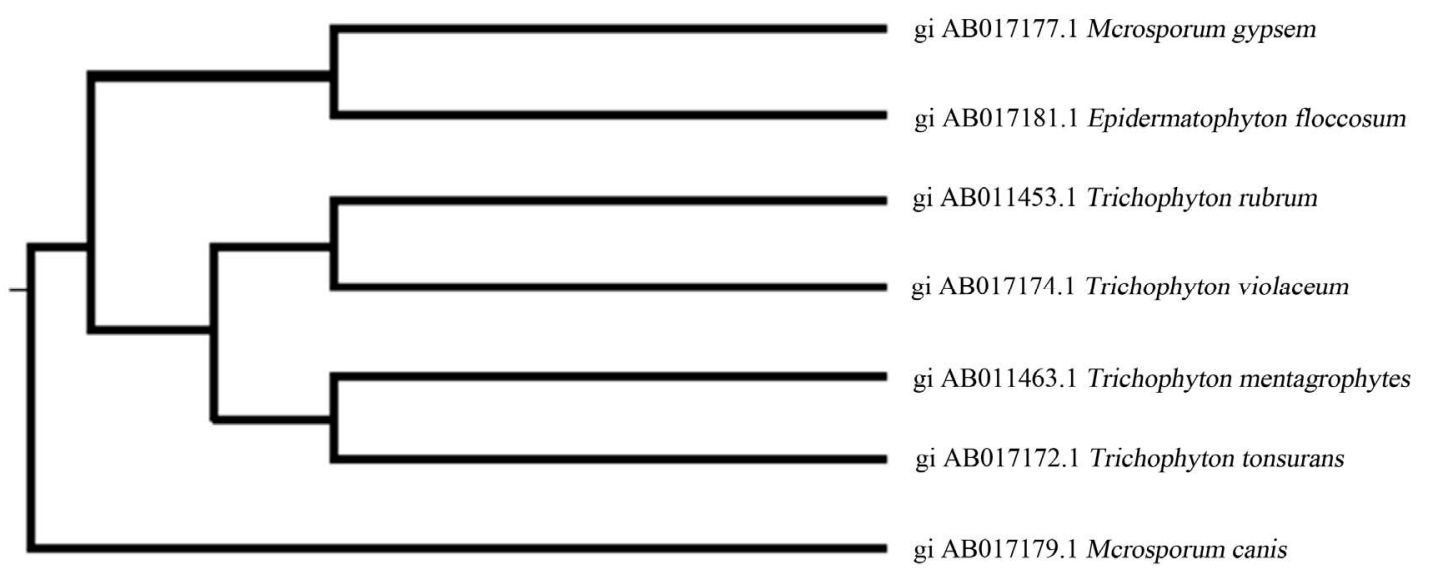

Figure 3. Result of cladogram (Neigbour Joining Tree plot) of dermatophytes on the basis of their ITS1 sequences. The NJ tree was constructed with data for standard strains of dermatophytes.

The oil at $2.5 \mu \mathrm{l} / \mathrm{ml}$ showed $100 \%$ inhibition against Microsporum gypsem, M. canis and Epidermatophyton floccosum which were closely placed in cladogram while 93\% and 94\% inhibition in T. violaceum and T. tonsurans and $100 \%$ static inhibition was found in Trichophyton mentagrophytes, T. rubrum which were clustered in cladogram as well (Figure 3). Further, evaluation of the phylogenetic analysis and identification system, both of which are based on ITS1 rDNA sequences, are continuing in our laboratory with other species and strains.

\section{Conclusion}

The findings of the present study shows that waste leaves oil of Psidium guajava L. is a promising antifungal agent that could be used as a therapeutic remedy against tinea pedis causing human dermatophytic fungi on account of its various in-vitro and in-vivo antifungal properties, viz., strong fungicidal action, long shelf-life, its tolerability of heavy inoculum density, thermostability, broad range of antidermatophytic activity and absence of any adverse effects. The effectiveness of waste leaf oil was in accordance with relationship of those dermatophytes which are close in phylogenetic tree. As such, the oil can be used as a potential source of effective and cheap herbal formulation after undergoing double blind successful multicentral topical testing.

\section{Acknowledgements}

Thanks are due to the Head, Department of Botany, University of Allahabad for providing the research facilities; Department of Science and Technology (DST), New Delhi for financial assistance and Dr. Ashok Sharma, Deputy Director \& Head, Department of Bioinformatics, Central Institute of Medicinal and Aromatic Plants (CIMAP), Lucknow for his invaluable support.

\section{REFERENCES}

[1] P. Kannan, C. Janaki and G. S. Selvi, "Prevalence of Dermatophytes and Other Fungal Agents Isolated from Clini- 
cal Samples," Indian Journal of Medical Microbiology, Vol. 24, No. 3, 2006, pp. 212-215.

[2] Y. M. Clayton, "Clinical and Mycological Diagnostic Aspect of Onychomycoses and Dermatomycoses," Clinical and Experimental Dermatology, Vol. 17, Suppl. 1, 1992, pp. 537-540. doi:10.1111/j.1365-2230.1992.tb00276.x

[3] R. C. Summerbell, J. Kane and S. Karjden, "Onychomycosis, Tinea Pedis, and Tinea Mannum Caused by NonDermatophyte Filamentous Fungi," Mycosis, Vol. 32, No 12, 1989, pp. 609-619. doi:10.1111/j.1439-0507.1989.tb02192.x

[4] M. A. Ghannoum and L. B. Rice, "Antifungal Agents: Mode of Action, Mechanisms of Resistance, and Correlation of These Mechanisms with Bacterial Resistance," Clinical Microbiology Reviews, Vol. 12, No. 4, 1999, pp. 501-517.

[5] A. C. Roxburg and P. Borrie, "Common Skin Disease," 7th Edition, The English Language Book Society and HK Lewis and Co. Ltd., London, 1973.

[6] B. Klink, "Alternative Medicines: Is Natural Really Better?" Drug Top, Vol. 141, 1997, pp. 99-100.

[7] F. Beye, "Insecticides from the Vegetable Kingdom," Plant Research and Development, Vol. 7, 1978, pp. 13-31.

[8] M. C. Pandey, J. R. Sharma and A. Dikshit, "Antifungal Evaluation of the Essential Oil of Cymbopogan pendulus (Nees ex Steud.) Wats a Parman," Flavour and Fragrance Journal, Vol. 11, No. 4, 1996, pp. 257-260. doi:10.1002/(SICI)1099-1026(199607)11:4<257::AID-FF J576>3.0.CO;2-5

[9] S. K. Shahi, A. C. Shukla, A. K. Bajaj, U. Banerjee, D. Rimek, G. Midgely and A. Dikshit, "Broad Spectrum Herbal Therapy against Superficial Fungal Infections," Skin Pharmacology and Applied Skin Physiology, Vol. 13, No. 1, 2000, pp. 60-64. doi:10.1159/000029909

[10] J. Alper, "Effort to Combat Microbial Resistance Lags," ASM News, Vol. 64, 1998, pp. 440-441.

[11] International Union for Conservation of Nature and Natural Resources (IUCN), "Guidelines on the Conservation of Medicinal Plants," IUCN, Gland, 1993.

[12] B. E. V. Wyk, B. V. Oudtshoorn and N. Gericke, "Medicinal Plants of South Africa," Briza Publications, Pretoria, 1997.

[13] R. Ticzon, "Ticzon Herbal Medicine Encyclopaedia," Romeo R. Ticzon Publishing, Philippines, 1997.

[14] M. P. G. Rosa, M. Sylvia and V. S. Rosario, "Psidium guajava: A Review of Its Traditional Uses, Phytochemistry and Pharmacology," Journal of Ethnopharmacology, Vol. 117, No. 1, 2008, pp. 1-27. doi:10.1016/j.jep.2008.01.025

[15] X. Lozoya, M. Meckes, M. Abou-Zaid, J. Tortoriello, C. Nozzolillo and J. T. Arnason, "Quercetin Glycosides in Psidium guajava L. Leaves and Determination of a Spasmolytic Principle," Archives of Medical Research, Vol. 25, No. 1, 1994, pp. 11-15.

[16] T. Tanaka, N. Ishida, M. Ishimatsu, G. Nonaka and I. Nishioka, "Tannins and Related Compounds. CXVI. Six New Complex Tannins, Guajavins, Psidins and Psiguavin from the Bark of Psidium guajava L.," Chemical \& Pharmaceutical Bulletin, Vol. 40, No. 8, 1992, pp. 2092-

\section{8. doi:10.1016/j.jep.2008.01.025}

[17] M. Meckes, F. Calzada, J. Tortoriello, J. L. González and M. Martinez, "Terpenoids Isolated from Psidium guajava Hexane Extract with Depressant Activity on Central Nervous System," Phytotherapy Research, Vol. 10, No. 7, 1996, pp. 600-603.

doi:10.1002/(SICI)1099-1573(199611)10:7<600::AID-PT R918>3.0.CO;2-7

[18] J. Li, F. Chen and J. Luo, "GC-MS Analysis of Essential Oil from the Leaves of Psidium guajava," Zhong Yao Cai, Vol. 22, No. 2, 1999, pp. 78-80.

[19] R. K. de Lima, M. D. G. Cardoso, M. A. Andrade, E. A. Nascimento, S. A. L. de Morais and D. L. Nelson, "Composition of the Essential Oil from Leaves of the Tree Domestic Varieties and One Wild Variety of the Guava Plant (Psidium guajava L., Myrtaceae)," Brazilian Journal of Pharmacognosy, Vol. 20, No. 1, 2010, pp. 41-44.

[20] A. Krishnamurthy, "Edited the Wealth of India," Raw Material, Vol. 8, 1969, pp. 287-292.

[21] J. F. Clevenger, "Apparatus for the Determination of Volatile Oil," Journal of the American Pharmaceutical Association, Vol. 17, No. 4, 1928, pp. 346-349.

[22] E. E. Langenau, "The Examination and Analysis of Essential Oils, Synthetics and Isolates," In: E. Guenther, Ed., The Essential Oils, Krieger Publishing Co., Huntington, 1948, pp. 227-348.

[23] R. K. Grover and J. D. Moore, "Toxicometric Studies of Fungicides against Brown Rot Organisms Sclerotinia fructicola and S. laxa," Phytopathology, Vol. 52, 1962, pp. 876880.

[24] S. K. Shahi, A. C. Shukla, A. K. Bajaj, G. Midgely and A. Dikshit, "Board Spectrum Antimycotic Drug for the Control of Fungal Infections in Human Beings," Current Science, Vol. 74, 1999, pp. 836-839.

[25] R. H. Garber and B. R. Houston "An inhibitor of Verticillium alboatrum in Cotton Seed," Phytopathology, Vol. 49, 1959, pp. 449-450.

[26] A. Dikshit and S. N. Dixit, "Cedrus Oil-A Promising Antifugal Agent," Bibliography of Indian Medicine, Vol. 26, 1982, pp. 226-227.

[27] K. Makimura, T. Mochizuki, A. Hasagawa, K. Uchida and H. Yamaguchi, "Phylogenetic Classification of Trichophyton mentagrophytes Complex Strains Based on DNA Sequences of Nuclear Ribosomal Internal Transcribed Spacer 1 Regions," Journal of Clinical Microbiology, Vol. 36, No. 1, 1998, pp. 2629-2633.

[28] E. Yoshidaa, K. Makimura, H. Mirhendi, T. Kaneko, M. Hiruma, T. Kasai, K. Uchida, H. Yamaguchi and R. Tsuboi, "Rapid Identification of Trichophyton tonsurans by Specific PCR Based on DNA Sequences of Nuclear Ribosomal Internal Transcribed Spacer (ITS) 1 Region," Journal of Dermatological Science, Vol. 42, No. 3, 2006, pp. 225-230. doi:10.1016/j.jdermsci.2005.12.014

[29] K. Makimura, Y. Tamura, T. Mochizuki, A. Hasegawa, Y. Tajiri, R. Hanazawa, K. Uchida, H. Saito and H. Yamaguchi, "Phylogenetic Classification and Species Identification of Dermatophyte Strains Based on DNA Sequences 
of Nuclear Ribosomal Internal Transcribed Spacer 1 Regions," Journal of Clinical Microbiology, Vol. 37, No. 4, 1999, pp. 920-924.

[30] D. Higgins, "Clustal W, Version 1.6," The European Bioinformatics Institute, Cambridge, 1996.

[31] J. Felsenstein, "PHYLIP (Phylogeny Inference Package)," Version 3.5c, University of Washington, Seattle, 1995.

[32] N. Saito and M. Nei, "The Neighbor-Joining Method: A New Method for Reconstructing Phylogenetic Trees," Molecular Biology and Evolution, Vol. 4, No. 4, 1987, pp. 406-425.

[33] M. Gouy, "NJPLOT," University of Lyon 1, Lyon, 1995.

[34] J. Felsenstein, "Confidence Limits on Phylogenies: An Approach Using the Bootstrap," Evolution, Vol. 39, No. 4, 1985, pp. 783-791. doi:10.2307/2408678

[35] R. Stock, "How Effective Are Antimycotic Drugs," Pharmaceutical International, Vol. 2, 1981, pp. 232-236.

[36] S. Begum, S. I. Hassan and B. S. Siddiqui, "Two New Triterpenoids from the Fresh Leaves of Psidium guajava," Planta Medica, Vol. 68, No. 12, 2002, pp. 11491152. doi:10.1055/s-2002-36353

[37] V. K. Kaul, S. S. Nigam and K. L. Dhar, "Antimicrobial Activities of the Essential Oils of Artemissia ibsintbium Linn., A. vestita Wall. and A. vulgaris Linn.," Indian Journal of Pharmaceutical Sciences, Vol. 38, 1976, pp. 21-23.

[38] A. K. Lahariya and J. T. Rao, "In-Vitro Antimicrobial Studies of the Essential oil of Cyperus scarious and Ocimum basilicum," Indian Drugs, Vol. 16, 1979, pp. 150-152.

[39] Y. Sim and S. Shin, "Combinatorial Anti-Trichophyton Effects of Ligusticum chuanxiong Essential Oil Components with Antibiotics," Archives of Pharmacal Research, Vol. 4, No. 4, 2008, pp. 497-502.

\section{doi:10.1007/s12272-001-1184-7}

[40] S. Inouye, Y. Nishiyama, K. Uchida and Y. H. H. Yamaguchi, "The Vapor Activity of Oregano, Perilla, Tea Tree, lavender, Clove, and Geranium Oils against a Trichophyton mentagrophytes in a Closed Box," Journal of Infection and Chemotherapy, Vol. 12, No. 6, 2007, pp. 349-354. doi:10.1007/s10156-006-0474-7

[41] M. S. Pyun and S. Shin, "Antifungal Effects of the Volatile Oils from Allium Plants against Trichophyton Species and Synergism of the Oils with Ketoconazole," Phytomedicine, Vol. 13, No. 6, 2006, pp. 394-400. doi:10.1016/j.phymed.2005.03.011

[42] M. J. Park, K. S. Gwak, I. Yang, W. S. Choi, H. J. Jo, J. W. Chang, E. B. Jeung and I. G. Choi, "Antifungal Activities of the Essential Oils in Syzygium aromaticum (L.) Merr. Et Perry and Leptospermum petersonii Bailey and Their Constituents against Various Dermatophytes," The Journal of Microbiology, Vol. 45, No. 5, 2007, pp. 460465.

[43] M. R. R. Silva, J. G. J. Oliveira, O. F. L. Fernandes, X. S. Passos, C. R. Costa, L. K. H. Souza, J. A. Lemos and J. R. Paula, "Antifungal Activity of Ocimum gratissimum towards Dermatophytes," Mycoses, Vol. 48, No. 3, 2005, pp. 172-175. doi:10.1111/j.1439-0507.2005.01100.x

[44] R. Chaturvedi, A. Dikshit and S. N. Dixit, "Adenocalymma allicea, a New Source of Natural Fungitoxicant," Tropical Agriculture, Vol. 64, 1987, pp. 318-322.

[45] R. K. Mishra, A. Kumar, A. C. Shukla, P. Tiwari and A. Dikshit, "Quantitative and Rapid Antibacterial Assay of Micromeria biflora Benth. Leaf Essential Oil against Dental Caries Causing Bacteria Using Phylogenetic Approach," Journal of Ecobiotechnology, Vol. 2, No. 4, 2010, pp. 22-26. 